Supporting Information

\title{
Best Practices for the Synthesis, Activation, and Characterization of Metal- Organic Frameworks
}

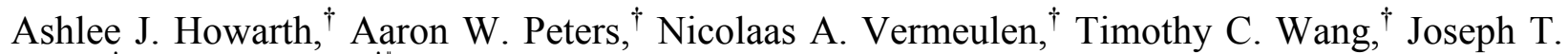
Hupp, ${ }^{\dagger}$ Omar K. Farha ${ }^{\dagger \dagger *}$

'Department of Chemistry, Northwestern University, 2145 Sheridan Road, Evanston, Illinois 60208, United States

"Department of Chemistry, Faculty of Science, King Abdulaziz University, Jeddah, Saudi Arabia

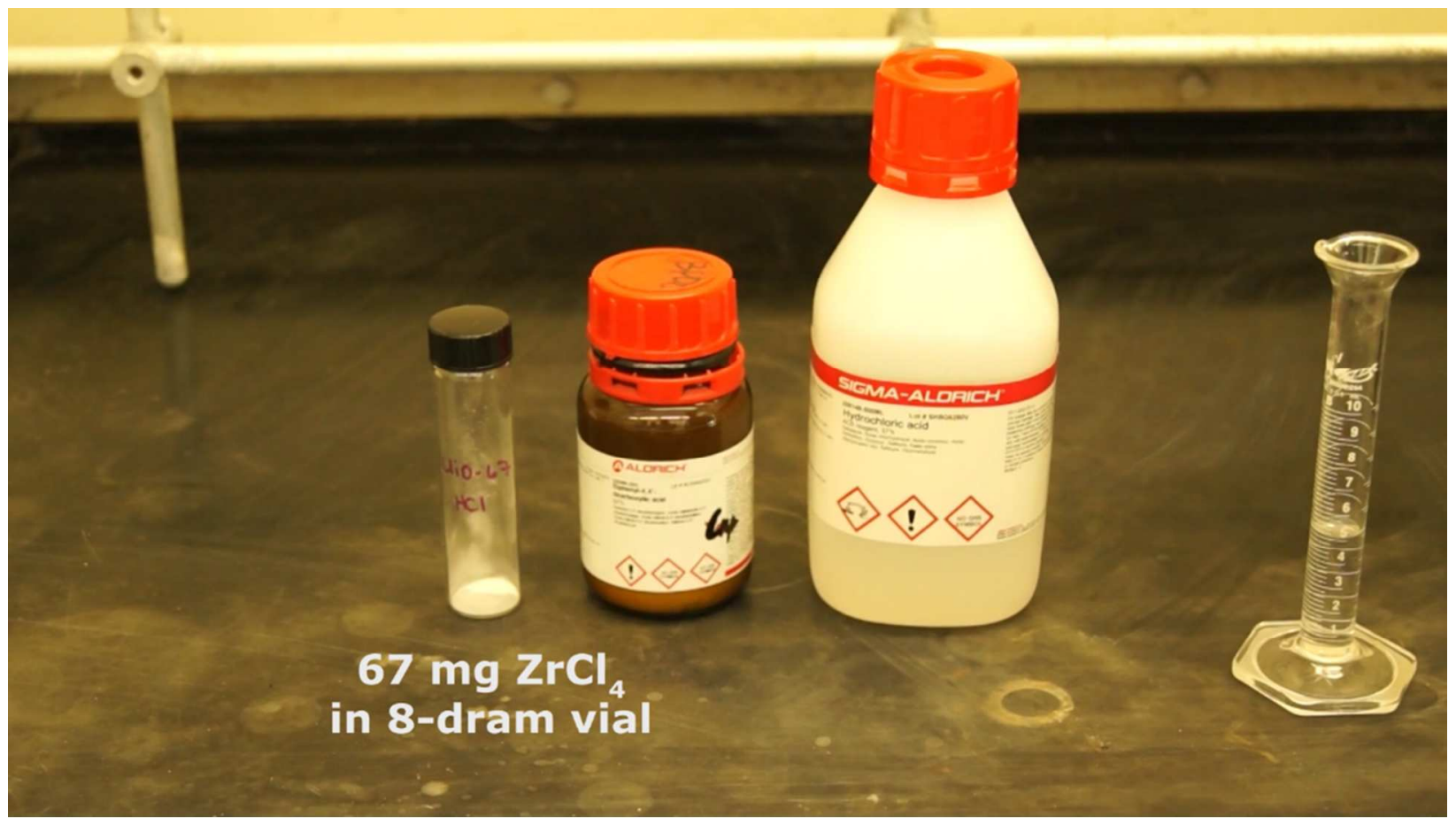

Video 1 - Preparation of UiO-67 using benzoic acid or $\mathrm{HCl}$ as a modulator 


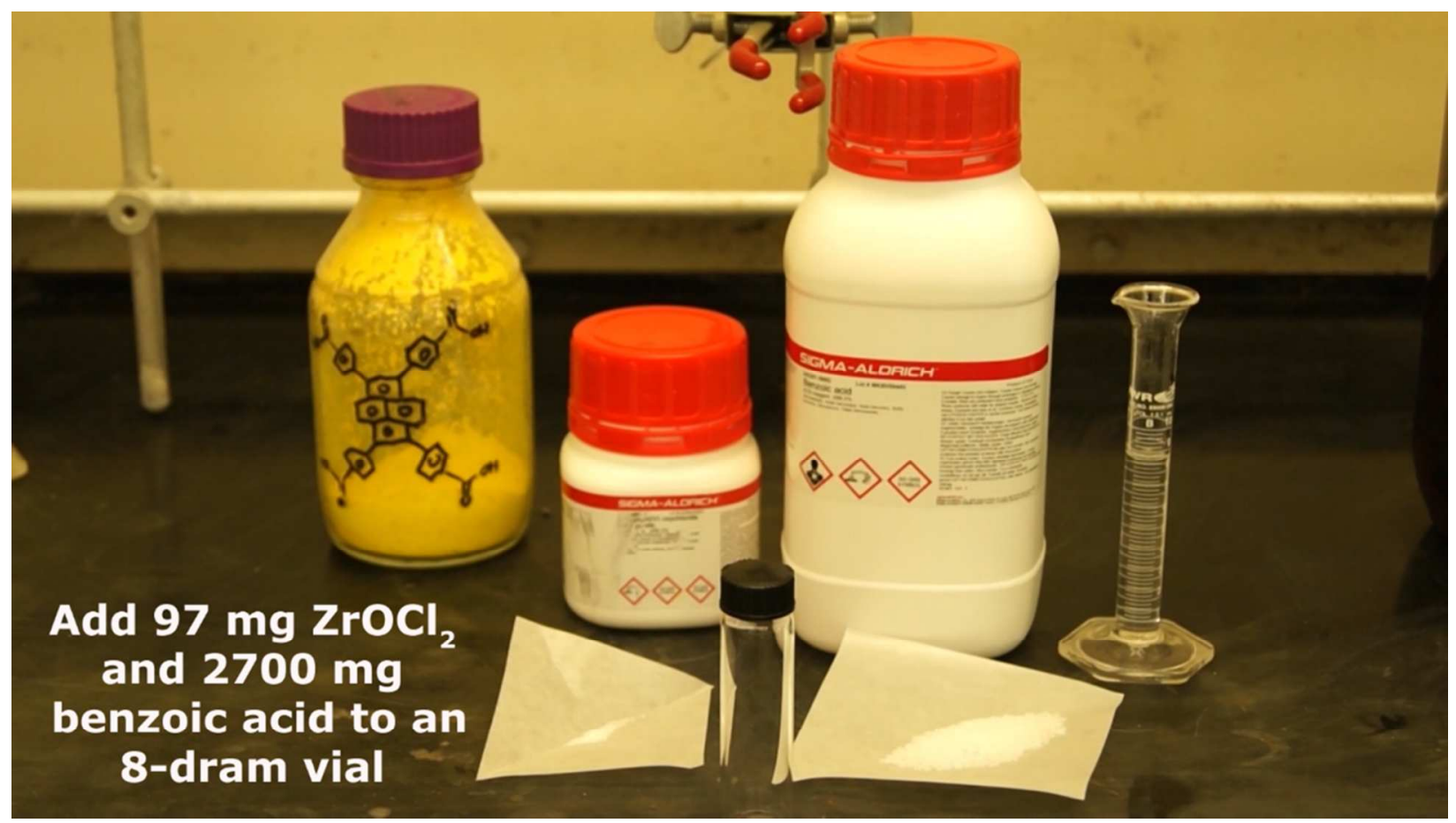

Video 2 - Synthesis of NU-1000

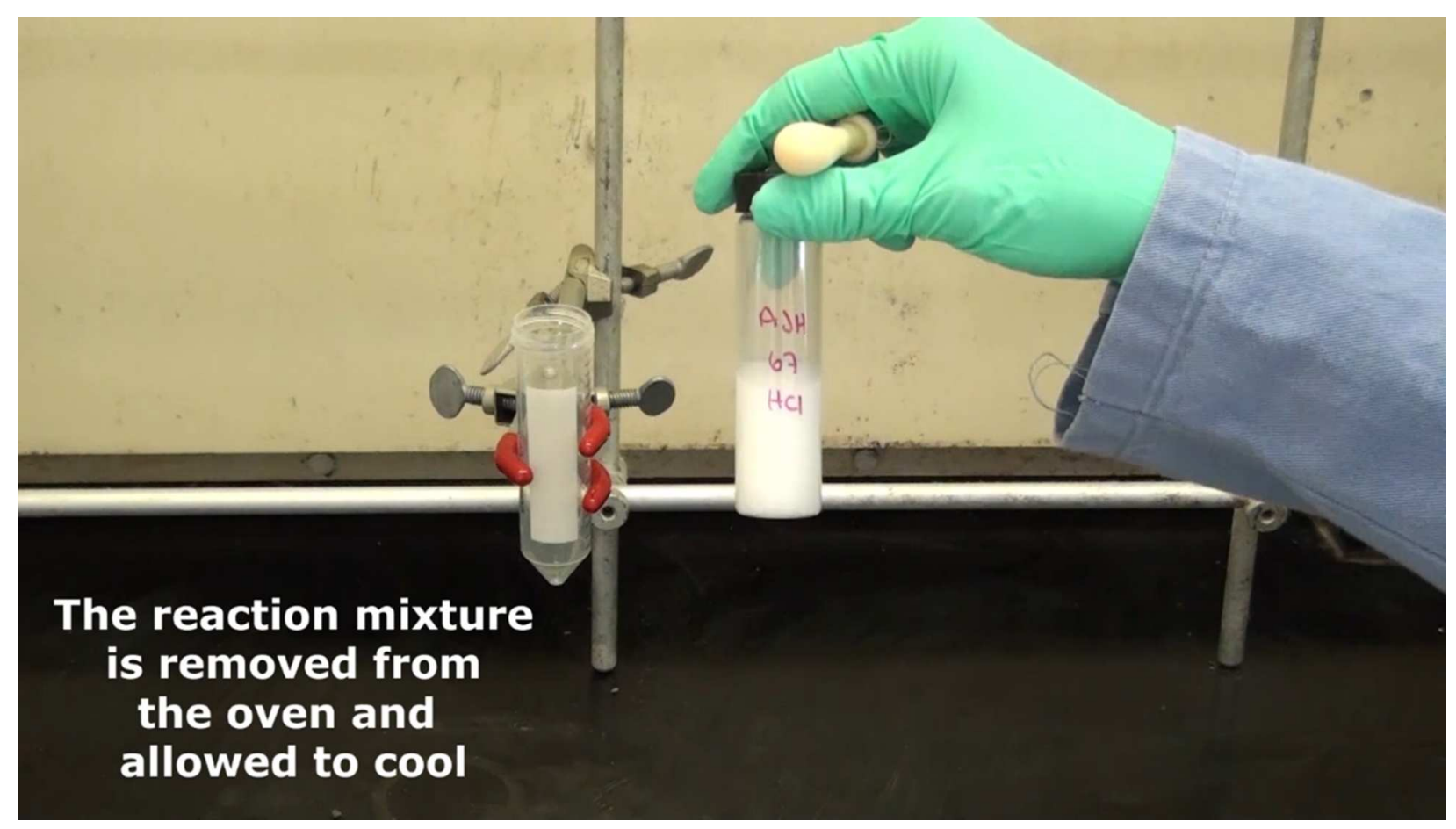

Video 3 - Solvent exchange 


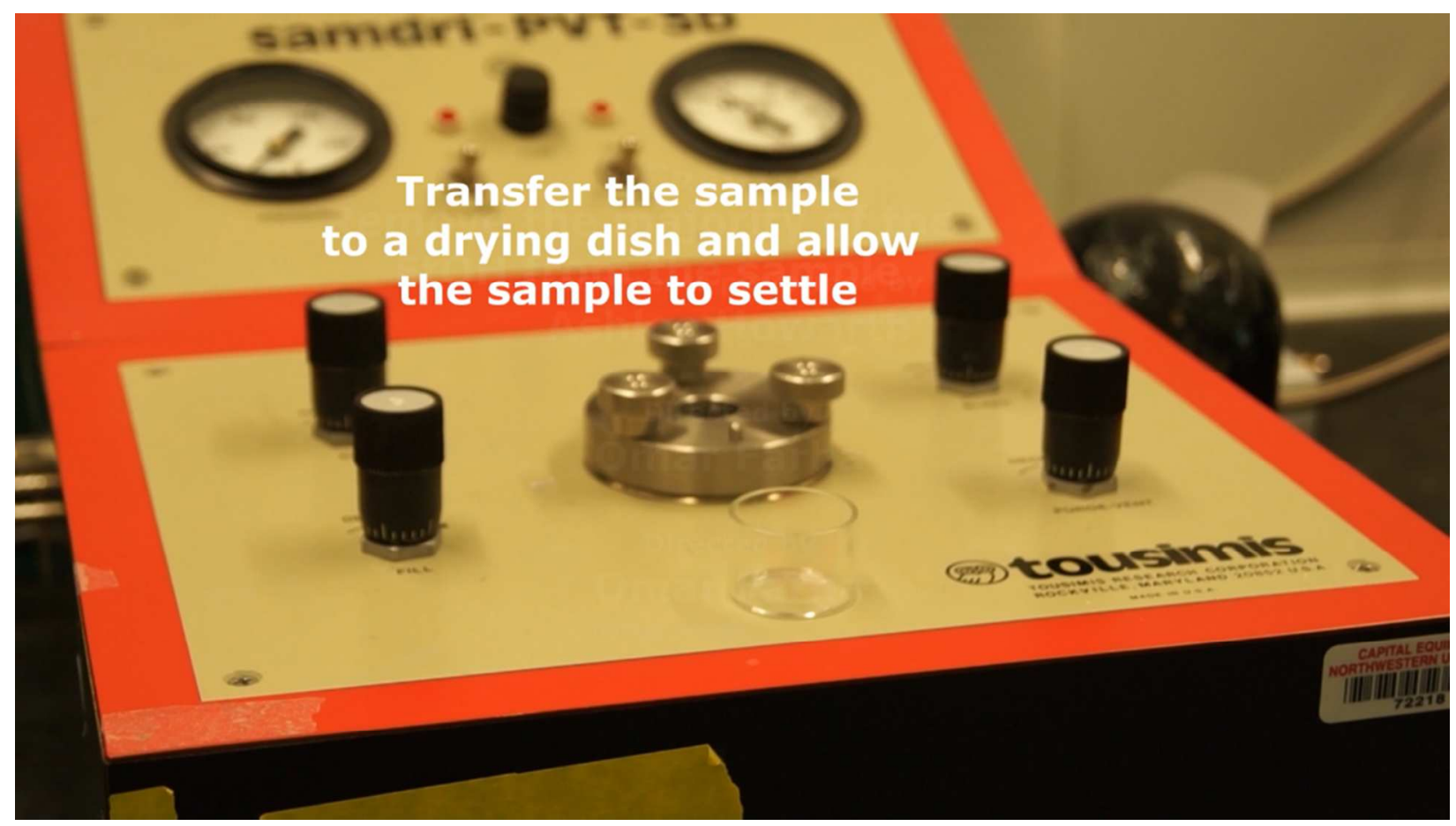

Video 4 - Supercritical $\mathrm{CO}_{2}$ activation

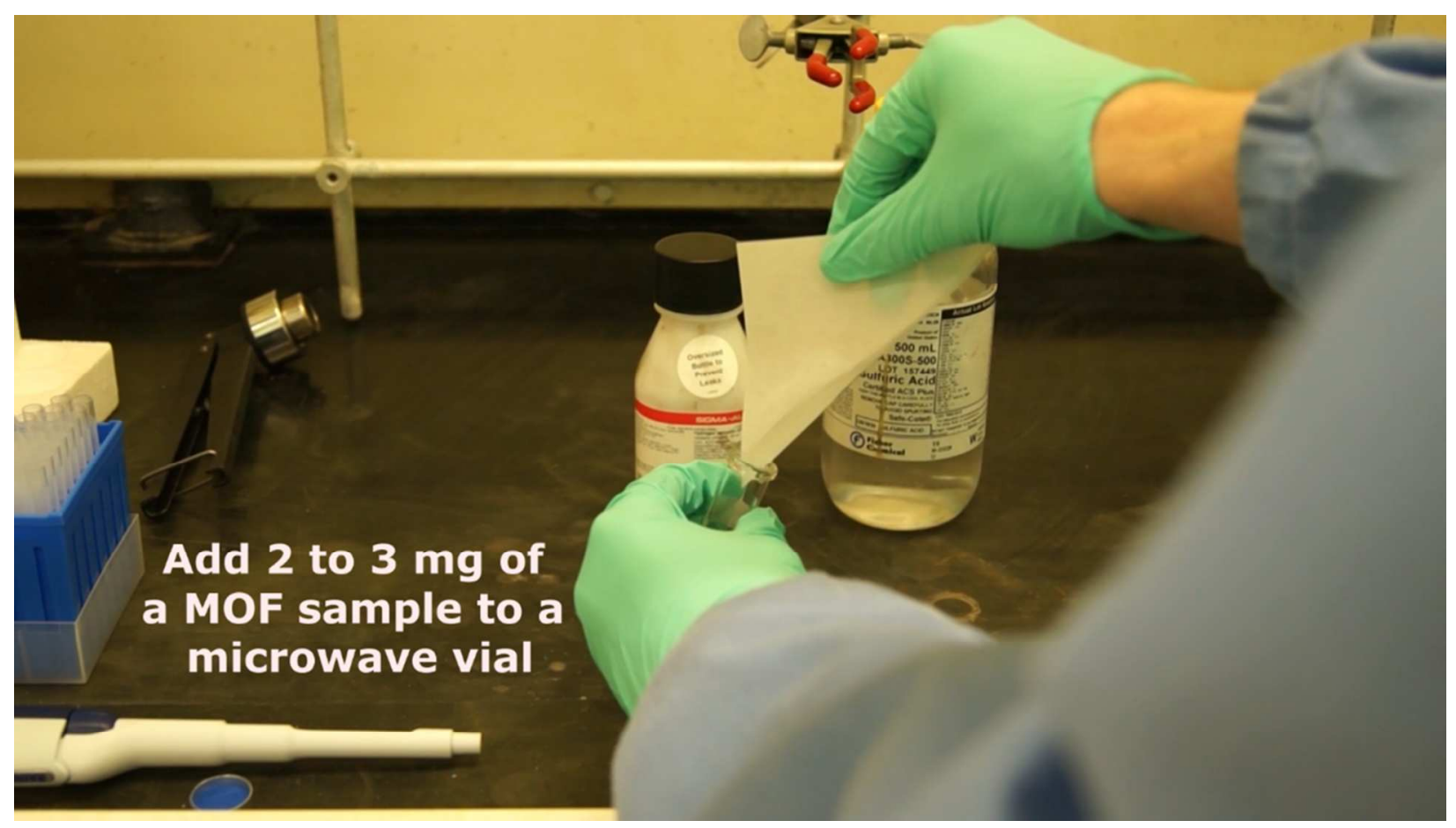

Video 5 - ICP sample digestion 